\title{
Editorial
}

\section{A Festive Celebration of Innovative Clinical Scholarship}

Elaine Hall

Northumbria University, UK

\section{Elaine.Hall@northumbria.ac.uk}

2016 has been a year 'packed with incident' ${ }^{1}$. Despite - or because of? -this, here at the IJCLE we have an embarrassment of riches in clinical scholarship with so many papers that an extra, festive, edition was needed! We are hoping to continue this level of publication in 2017, so please keep your papers coming.

We begin with a paper developed from the opening keynote speech at the IJCLE/ACCLE conference in Toronto last July. Sarah Buhler's rousing and inspiring perspective on Clinical Legal Education in a Dangerous Time has become, if anything, more relevant in the intervening months.

Typifying the clinician's resilience in the face of challenging circumstances, the integrating theme of our papers and practice reports is innovation. Les McCrimmon, Ros Vickers and Ken Parish offer a dissection of the emerging field of online legal education, with an overview of the field and a case example from Australia that raise a number of important pedagogical and practical questions. Online legal study may

\footnotetext{
${ }^{1}$ A staggering understatement, but it was that or a very long rant.
} 
be in its' infancy, however this paper challenges us all to consider how it could develop.

David Collins, Eric Klotz and Ben Robinson add to our growing body of work on business clinics ${ }^{2}$ with their analysis of the role of law clinics in supporting innovation through advice to commercial start-ups. This paper contains a very useful analysis drawn from the wealth of data the clinic collected from their clients, a fantastically useful model for us all in building our empirical research base.

Our Practice Report from Kenya highlights the limitations that clinics operate within, particularly in terms of their relationships with Universities and calls for new structures to support development.

\footnotetext{
2 For example, Campbell, Elaine (2016) Recognizing the Social and Economic Value of Transactional Law Clinics: A View from the United Kingdom. Journal of Legal Education, 65 (3). pp. 580-596.
} 
A reminder that three organisations are coming together for the 2017 conference. We look forward to welcoming you to Newcastle!

\section{IJCLE - ENCLE - CLEO}

The International Journal of Clinical Legal Education in association with the

European Network for Clinical Legal Education and the

United Kingdom Clinical Legal Education Organisation

\section{CONFERENCE 3-5 JULY 2017}

at the University of Northumbria, Newcastle upon Tyne, UK

"Bringing It All Together: Clinical Legal Educators in the 21st Century University"

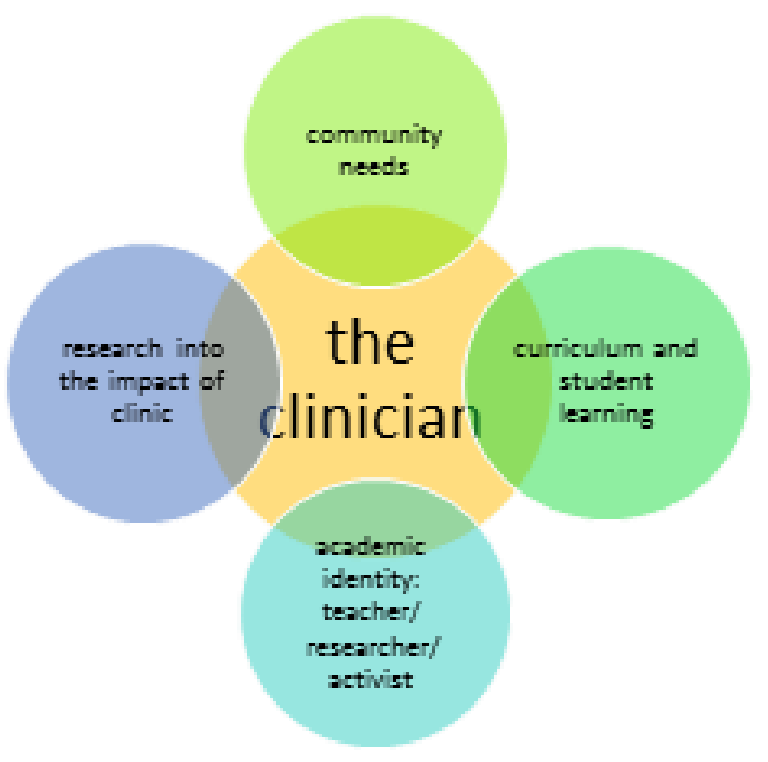


Clinicians wear many hats: teacher, group facilitator, project manager, lawyer, researcher, mentor, activist, administrator, supervisor, academic, fund raiser, practice manager, collaborator, role model, counsellor...

This year's conference continues our exploration of the key, often overlapping, issues arising for clinical legal education in the $21^{\text {st }}$ century from the clinician's perspective; juggling sometimes competing priorities and often making difficult choices. Papers are invited which consider one or more of these themes below while still encouraging participants to locate their papers either mainly in one of those areas or by exploring the overlaps.

Themes:

- The clinician and community needs

- The clinician and research into the impact of clinic

- The clinician and academic identity

- The clinician and curriculum and student learning

In particular, we would like to encourage participants to include student and other partners' voices in their presentations, ideally through collaborative writing and presentation in person or through video calling or recordings.

\section{Taking part}

Presentations at IJCLE/ENCLE/CLEO can take one of three formats, each with its own structured proposal application form:

- Paper presentation 
- These will be in traditional conference paper format, with a twenty minute presentation followed by questions. Participants will be invited to indicate if their paper falls into one or more of the four areas: Community Need; Curriculum and Students; Academic Identity; Research and Impact.

- Interactive seminar

- These sessions will be 90 minutes long, will involve active participation from the audience as well as input from the presenters and will be designed to generate discussion and new learning for the participants and the convenors. Participants will be invited to indicate if their seminar falls into one or more of the four areas: Community Need; Curriculum and Students; Academic Identity; Research and Impact.

- PechaKucha

- A PechaKucha consists of 20 slides timed to change every 20 seconds, so each presentation lasts 6 minutes and 40 seconds. Each presenter in PechaKucha session will be assigned a 10 minute slot to allow for a question to be posed. We anticipate that PechaKuchas will consist of short introductions to new work, methodological innovations or insights from the field. Please follow this link to learn more. Participants are encouraged to offer PechaKuchas in addition to traditional papers. 


\section{Key Dates}

- Call for papers, seminars and PechaKucha opens - November 21, 2016. Please follow this link to submit and learn more.

- $\quad$ Call for papers, seminars and PechaKucha closes - January 31, 2017

- Confirmation of papers, seminars and PechaKucha accepted for the conference rolling through December and no later than February 10, 2017

- $\quad$ Registration opens - January 162017

- $\quad$ Early-bird registration closes - March 3, 2017

- $\quad$ Registration closes - June 2, 2017

- $\quad$ Deadline for submission of papers and outlines to website. - June 9, 2017 